\title{
Gambaran Diagnostik dan Penatalaksanaan Gastritis Rawat Inap BPJS di RSU Royal Prima Medan Tahun 2017
}

\author{
Ricky Kristhanser Ndruru1, Syahrial Sitorus ${ }^{2}$, Nerseri Barus ${ }^{3}$ \\ Prodi Kedokteran Umum, Fakultas Kedokteran, Universitas Prima Indonesia ${ }^{1,2,3}$ \\ rickykristh@gmail.com
}

\begin{abstract}
Abstrak
Gastritis adalah penyakit dengan inflamasi pada mukosa lambung. Tujuan dari penelitian ini adalah untuk mengetahui gambaran diagnostik dan penatalaksanaan dari gastritis rawat inap BPJS di Rumah Sakit Umum Royal Prima Medan pada tahun 2017. Penelitian ini dilakukan dengan menggunakan dengan menggunakan design studi kasus, deskripif - retrospektif, besar sampel adalah 100 data rekam medis pasien, diambil secara purposive sampling, yaitu rekam medis yang paling lengkap dan dianalisa dengan deskriptif stastik. Pada hasil ditemukan umur termuda yaitu 16 tahun dan umur tertua 72 tahun, dengan jumlah laki - laki sebanyak 32 orang dan perempuan sebanyak 68 orang. Keluhan utama paling banyak datang ialah nyeri ulu hati sebanyak 96 orang dan penatalaksanaan famakologis terbanyak adalah antasida + omeprazole + domperidone + ranitidine yaitu sebanyak 46\% dari 100\% terapi yang diberikan. Kesimpulan yang didapatkan ialah bahwa distribusi terjadinya gastritis lebih tinggi terjadi pada perempuan (68\%) dari pada laki - laki (32\%) dan keluhan terbanyak datang ialah nyeri ulu hati (96\%), dan terapi kombinasi paling banyak adalah dengan menggunakan antasida + omeprazole + domperidone + ranitidine $(46 \%)$.
\end{abstract}

Kata Kunci: Gastritis, Dignostik, Penatalaksanaan

\begin{abstract}
Gastritis is an inflammatory disease of the gastric mucosa. This research is to find the description of diagnostic and management of BPJS in patient gastritis at the Royal Prima Medan General Hospital in 2017. A research use a case study design, descriptive - retrospective, and take 100 medical record of the pastient as a sample by using purposive sampling, it is the most complete medical record and analyzed with descriptive statistic. The result shows that the youngest is 16 yeasr old and the oldest is 72 years old. The main general complaints were most heartburn 96 patients and most pharmacological therapy is antacid + omeprazole + domperidone + ranitidine with $46 \%$ from 100\%. The conclution is the distribution of gastritis in woman (68\%) is higher than in men (32\%), the main general complaints were most heartburn (96\%) and most pharmacological therapy is antacid + omeprazole + domperidone + ranitidine (46\%).
\end{abstract}

Keywords: Gastritis, Diagnostic, Therap 


\section{Pendahuluan}

Gastritis ialah suatu inflamasi yang mengenai daerah dinding lambung terutama pada mukosa gaster ${ }^{1}$. Gastritis dapat disebabkan oleh beberapa hal seperti oleh karena infeksi H.pylori, kebiasaan makan makanan yang pedas, asam, minuman iritatif (seperti soda), serta konsumsi kopi, alcohol, stress emosional, obat - obatan seperti NSAID, dan juga dapat disebabkan oleh karena imunitas.

Berdasarkan penelitian yang telah dilakukan oleh World Health Organization (WHO), didapati kejadian gastritis di beberapa negara seperti, Inggris $22 \%$, China $31 \%$, Jepang 14,5 \%, Kanada $35 \%$ dan Perancis 29,5. Sedangkan, untuk di Asia Tenggara gastritis mencapai angka sekitar 583.635 kasus dari jumlah penduduk setiap tahunnya ${ }^{2}$.

Data dari Kemenkes RI mendapati bahwa Indonesia menempati urutan keempat sebagai negara dengan kasus gastritis tertinggi setelah Amerika, Inggris, dan Bangladesh, serta merupakan penyakit yang menempati posisi kelima dari sepuluh besar penyakit pasien rawat inap dan posisi keenam dalam urutan penyakit pasien rawat jalan di rumah sakit ${ }^{3}$.

Badan Penyelenggara Jaminan Sosial (BPJS) adalah suatu badan hukum yang dibentuk untuk menyelenggarakan program jaminan sosial berupa suatu bentuk perlindungan sosial untuk menjamin seluruh rakyat agar dapat memenuhi kebutuhan dasar hidupnya dengan layak. BPJS terbagi atas dua, yaitu BPJS Kesehatan dan BPJS Ketenagakerjaan. BPJS Kesehatan adalah badan publik yang menyelenggarakan program Jaminan Kesehatan, sedangkan BPJS
Ketenagakerjaan adalah badan publik yang menyelenggarakan program jaminan kecelakaan, jaminan hari tua, jaminan pensiun, dan jaminan kematian ${ }^{4}$.

Semua pasien yang dicurigai gastritis yang datang dengan penurunan keaadan dan memerlukan perawatan dari tenaga medis diindikasikan harus lah di lakukan perawatan rawat inap. Penurunan keadaan tersebut dapat berupa demam, pusing, mual, nyeri ulu hati serta badan yang lemah ${ }^{5}$.

Gambaran diagnostik pasien adalah dinilai berdasarkan keluhan utama, keluhan tambahan, pemeriksaan fisik, dan pemeriksaan penunjang. Penatalaksanaan adalah tindakan yang dilakukan terhadap pasien.

Pada dasarnya, tata cara diagnostik dan penatalaksanaan dari gastritis ini sudahlah diketahui, namun karena adanya perkembangan dari pada ilmu pengetahuan dan teknologi dalam bidang kedokteran, menyebabkan munculnya beberapa perubahan serta berbagai variasi tata cara diagnosa dan penatalaksanaan gastritis berdasarkan waktu, tempat dan situasi yang berbeda, terlebih lagi di era BPJS yang semakin marak menjadi bahan perbincangan. Oleh karena itu, timbul pertanyaan bagaimana gambaran diagnostik dan penatalaksanaan pasien gastritis rawat inap BPJS di Rumah Sakit Umum Royal Prima Medan. Oleh karena itu, perlulah sekiranya di lakukan penelitian untuk dapat mengetahui gambaran diagnostik dan penatalaksanaan pasien gastritis rawat inap BPJS di Rumah Sakit tersebut pada tahun 2017.

\section{Metode}

Jenis penelitian yang digunakan adalah penelitian dengan design studi kasus yang 
Ricky Kristhanser Ndruru, Syahrial Sitorus, Nerseri Barus. Gambaran Diagnostik dan Penatalaksanaan Gastritis Rawat Inap BPJS di RSU Royal Prima Medan Tahun 2017

DOI:

bersifat deskriptif dan retrospektif. Penelitian ini berdasarkan pada data rekam medis terkait gambaran diagnostik dan penatalaksanaan pasien gastritis rawat inap BPJS di Rumah Sakit Umum Royal Prima tahun 2017.

Penelitian dilakukan di Rumah Sakit Umum Royal Prima Medan dengan pertimbangan bahwa di Rumah Sakit Umum Royal Prima Medan tahun 2017 ada tersedia data pasien yang dibutuhkan. Waktu penelitian dimulai pada bulan Oktober hingga bulan Februari. Adapun yang menjadi populasi target adalah Pasien rawat inap BPJS dengan gastritis, dan yang menjadi populasi terjangkau adalah seluruh data rekam medis pasien gastritis rawat inap BPJS di Rumah Sakit Umum Royal Prima Medan tahun 2017. Besar sampel sesuai dengan tujuan penelitian untuk mencari proporsi, maka sampel yang dibutuhkan minimal berjumlah sebanyak 100 data dan diambil 100 data rekam medis pasien dengan gastritis rawat inap BPJS dari total keselurahan 329 data rekam medis pasien gastritis rawat inap BPJS yang ada.

Metode Pengumpulan data dilakukan dengan cara purposive sampling, yaitu rekam medis yang paling lengkap datanya. Analisa data dilakukan dengan manual, dan kemudian data dianalisis dengan cara deskriptif statistik distribusi proporsi dan disajikan dalam bentuk narasi, tabel distribusi proporsi dan gambar

\section{Hasil}

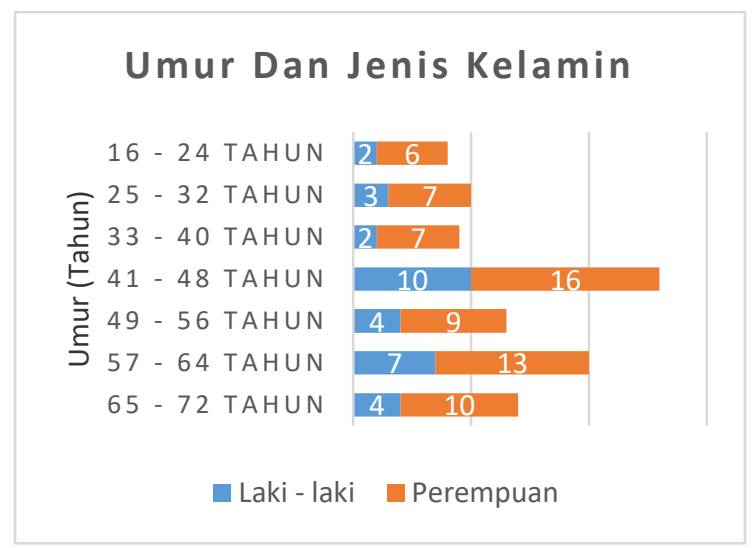

Gambar 1. Distribusi Proporsi Pasien Gastritis Rawat Inap BPJS Berdasarkan Umur dan Jenis Kelamin di RSU Royal Prima Medan Tahun 2017.

Proporsi terbanyak adalah kelompok umur 41 - 48 tahun (26\%) dengan laki - laki (10\%) dan perempuan (16\%), kemudian diikuti dengan kelompok umur 57 - 64 tahun (20\%) dengan laki - laki (7\%) dan perempuan (13\%), kelompok umur $65-72$ tahun (14\%) dengan laki - laki (4\%) dan perempuan (10\%), kelompok umur 49 - 56 tahun (13\%) dengan laki - laki (4\%) dan perempuan (9\%), kelompok umur 25 32 tahun (10\%) dengan laki - laki (3\%) dan perempuan (7\%), kelompok umur 33 - 40 tahun (9\%) dengan laki - laki (2\%) dan perempuan (7\%), dan proporsi paling sedikit adalah kelompok umur 16 - 24 tahun (8\%) dengan laki - laki (2\%) dan perempuan (6\%).

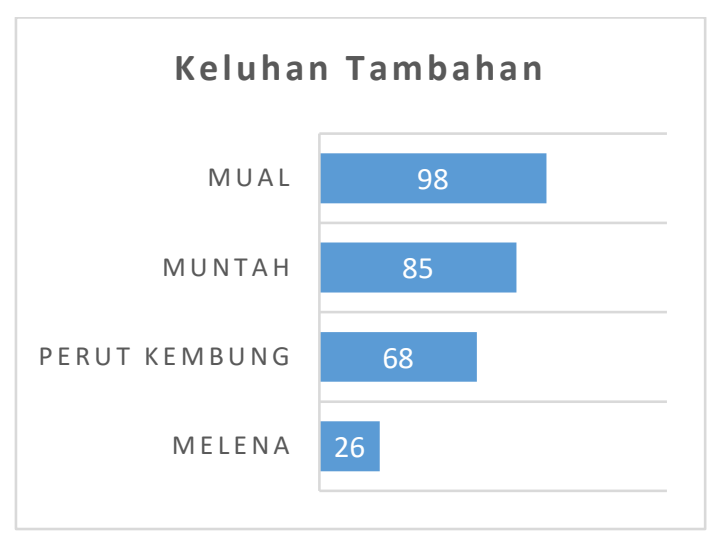

Gambar 2. Distribusi Proporsi Pasien Gastritis Rawat Inap BPJS Berdasarkan Keluhan Tambahan di RSU Royal Prima Medan Tahun 2017. 
Berdasarkan keluhan utama yang terbanyak adalah nyeri ulu hati (96\%) dan yang paling sedikit adalah muntah (4\%). Proporsi berdasarkan keluhan tambahan terbanyak adalah mual (98\%), diikuti muntah (85\%), perut kembung $(68 \%)$, dan yang paling sedikit adalah melena $(26 \%)$.

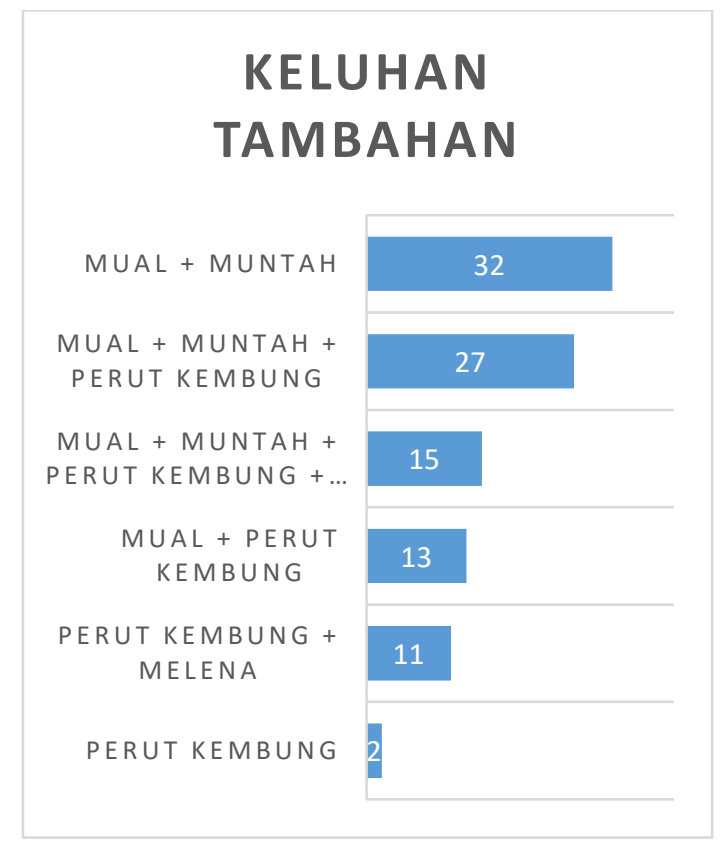

Gambar 3. Distribusi Proporsi Pasien Gastritis Rawat Inap BPJS Berdasarkan Keluhan Tambahan Setiap Pasien di RSU Royal Prima Medan Tahun 2017.

Distribusi proporsi berdasarkan kombinasi kombinasi keluhan tambahan yang terbanyak adalah mual + muntah $(32 \%)$, diikuti dengan mual + muntah + perut kembung $(27 \%)$, mual + muntah + perut kembung + melena $(15 \%)$, mual + perut kembung $(13 \%)$, perut kembung + melena $(11 \%)$, dan yang paling sedikit adalah perut kembung (2\%).

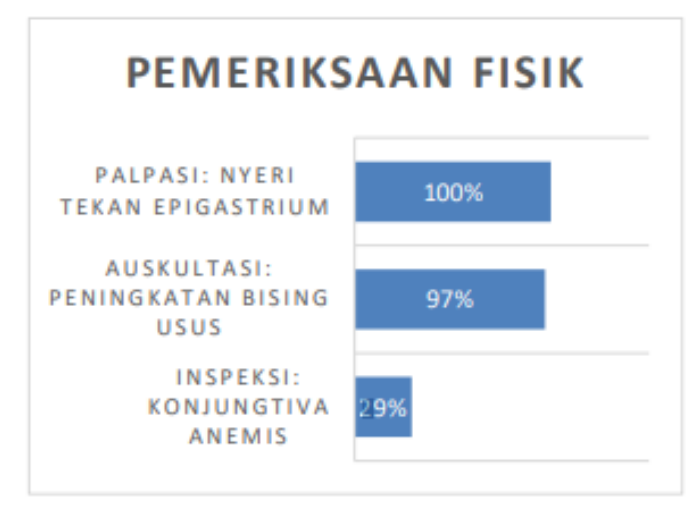

Gambar 4. Distribusi Proporsi Pasien Gastritis Rawat Inap BPJS Berdasarkan Pemeriksaan Pemeriksaan Fisik di RSU Royal Prima Medan Tahun 2017.

Distribusi proporsi pasien berdasarkan inspeksi, didapati pada pasien adanya konjungtiva anemis (29\%). Distribusi proporsi pasien berdasarkan auskultasi, didapati pada pasien adanya peningkatan bising usus (97\%). Distribusi proporsi pasien berdasarkan palpasi, didapati pada pasien adanya nyeri tekan epigastrium (100\%)

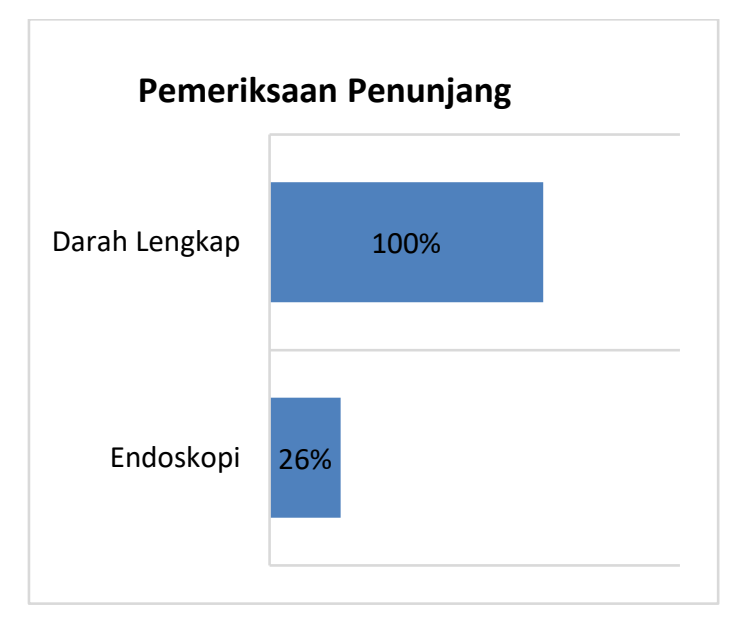

Gambar 5. Distribusi Proporsi Pasien Gastritis Rawat Inap BPJS Berdasarkan Pemeriksaan Penunjang

Proporsi pasien berdasarkan pemeriksaan penunjang terbanyak adalah darah lengkap (100\%) dan yang paling sedikit adalah endoskopi (26\%) 
Ricky Kristhanser Ndruru, Syahrial Sitorus, Nerseri Barus. Gambaran Diagnostik dan Penatalaksanaan Gastritis Rawat Inap BPJS di RSU Royal Prima Medan Tahun 2017 DOI:

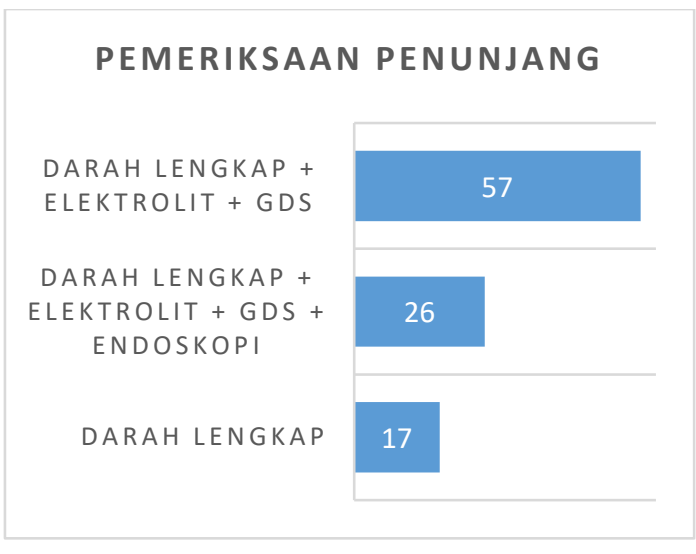

Gambar 6. Diagram Bar Distribusi Proporsi Pasien Gastritis Rawat Inap BPJS Berdasarkan Pemeriksaan Penunjang Setiap Pasien di RSU Royal Prima Medan Tahun 2017.

Distribusi proporsi berdasarkan pemeriksaan penunjang masing - masing pasien ditemukan pemeriksaan penunjang terbanyak adalah darah lengap + elektrolit + GDS + endoskopi (57\%) dan yang paling sedikit adalah darah lengap (17\%).

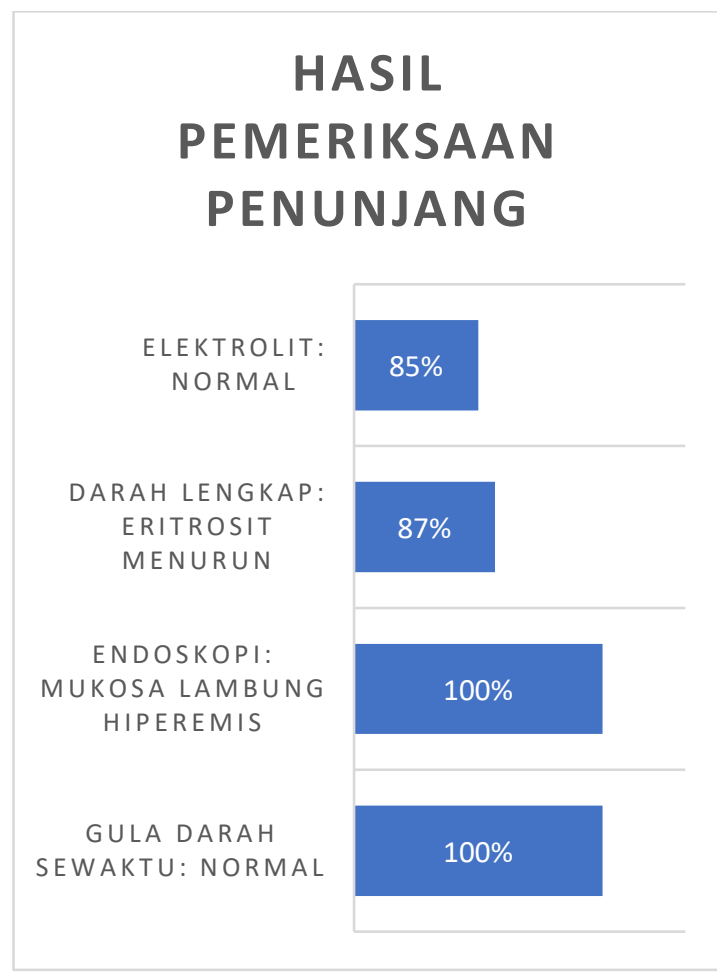

Gambar 7. Distribusi Proporsi Pasien Gastritis Rawat Inap BPJS Berdasarkan Hasil Pemeriksaan Penunjang di RSU Royal Prima Medan Tahun 2017.
Berdasarkan hasil pemeriksaan elektrolit yang terbanyak didapati adalah elektrolit dalam batas normal (85\%) dan yang paling sedikit adalah adanya ketidakseimbangan elektrolit dalam tubuh $(15 \%)$.

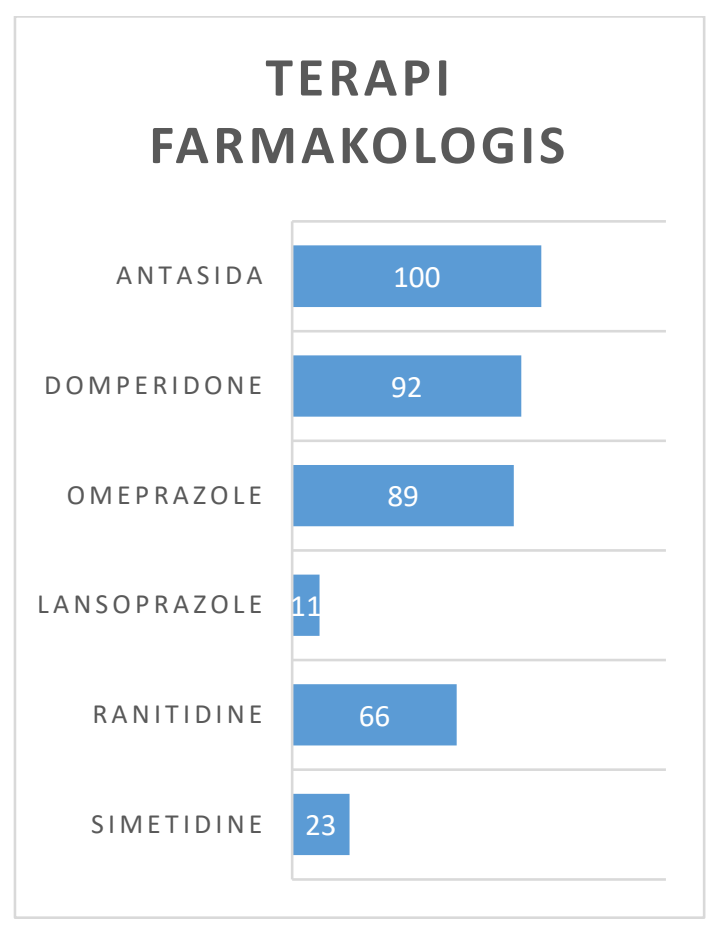

Gambar 9 Distribusi Proporsi Pasien Gastritis Rawat Inap BPJS Berdasarkan Terapi Farmakologis Kombinasi Setiap Pasien di RSU Royal Prima Medan Tahun 2017.

Berdasarkan terapi farmakologis kombinasi, yang terbanyak diberikan kepada pasien adalah Antasida + Omeprazole + Domperidone + Ranitidine $(46 \%)$ dan yang paling sedikit diberikan adalah Antasida + Omeprazole + Ranitidine (9\%).

Tabel 1 Lama rawatan Pasien Gastritis Rawat Inap BPJS yang Dirawat di RSU Royal Prima Medan Tahun 2017.

\begin{tabular}{lc}
\hline \multicolumn{2}{l}{ Lama Rawatan (Hari) } \\
\hline Maksimum & 7 \\
Minumun & 1 \\
Rata - Rata & 3 \\
\hline
\end{tabular}


Dari hasil penelitian ditemukan bahwa lama rawatan rata - rata adalah 3 hari, lama rawatan tersingkat adalah 1 hari dan lama rawatan terlama adalah 7 hari. Pada pasien dengan lama rawatan terlama adalah seorang pasien perempuan dengan umur 42 tahun. Dan pasien dengan lama rawatan 1 hari berjumlah 2 kasus.

Banyak faktor yang berkontribusi terhadap terjadinya gastritis diantaranya adalah umur, jenis kelamin, penyakit penyerta, dan daya tahan tubuh. Faktor - faktor tersebut secara tidak langsung juga berpengaruh terhadap lama rawat inap pasien gastritis di rumah sakit.

Tabel 2. Distribusi Proporsi Pasien Gastritis

Rawat Inap BPJS Berdasarkan Keadaan

Sewaktu Pulang yang Dirawat di RSU Royal Prima Medan Tahun 2017.

\begin{tabular}{lll}
\hline $\begin{array}{l}\text { Keadaan Sewaktu } \\
\text { Pulang }\end{array}$ & N & \% \\
\hline Sembuh & 81 & 81 \\
$\begin{array}{l}\text { Berobat Jalan } \\
\text { Pulang Atas Permintaan }\end{array}$ & 9 & 9 \\
Sendiri & 10 \\
\hline
\end{tabular}

Distribusi proporsi pasien gastritis rawat inap BPJS berdasarkan keadaan sewaktu pulang di RSU Royal Prima Medan Tahun 2017 yang terbanyak adalah sembuh (81\%) dan yang paling sedikit adalah berobat jalan (9\%).

\section{Pembahasan}

Berdasarkan hasil penelitian diatas didapati bahwa penderita gastritis tertinggi adalah perempuan (68\%), hal ini kemungkinan disebabkan oleh kebiasaan makan yang tidak baik dan tingginya tingakatan stres yang dialami. Hal ini juga didukung oleh penelitian yang dilakukan oleh Gustin yang mana 70\% dari responden penelitiannya adalah berjenis kelamin perempuan ${ }^{2}$.

Berdasarkan keluhan utama yang terbanyak adalah nyeri ulu hati (96\%) dan yang paling sedikit adalah muntah (4\%). Nyeri pada ulu hati (epigastrium) dapat berasal dari nyeri visceral abdomen akibat rangsang mekanis (regangan, spasme) sampai kepada rangsangan kimiawi (inflamasi, iskemia) ${ }^{6}$.

Mual adalah suatu sensasi tidak enak dibagian tenggorokan dan epigastrium yang berhubungan dengan keinginan untuk muntah. Hal ini terjadi akibat perubahan aktivitas saluran cerna seperti menigkatnya salivasi, menurunnya tonus lambung dan peristaltik ${ }^{7}$.

Muntah adalah suatu refleks yang menyebabkan dorongan ekspulsi isi lambung atau usus atau keduanya ke mulut. Hal ini terjadi akibat rangsangan pada pusat muntah di daerah postrema medula oblongata di dasar ventrikel ke empat. Jalur eferen menerima sinyal dan menyebabkan terjadinya gerakan ekspulsif otot abdomen, gastrointestinal dan pernapasan yang terkoordinasi dengan epifenomena emetik yang menyebabkan muntah ${ }^{7}$.

Berdasarkan hasil pemeriksaan darah lengkap yang terbanyak yaitu di dapati adanya penurunan kadar eritrosit dalam darah $(87 \%)$ dan yang paling sedikit adalah hasil normal (13\%). Secara umum nilai $\mathrm{Hb}$ dan Hct digunakan untuk memantau derajat anemia, yang terutama pengaruhnya pada gastritis adalah yang terkait dengan anemia pernisiosa ${ }^{8}$.

Berdasarkan hasil pemeriksaan GDS didapati GDS normal (100\%). Diabetes Melitus (DM) merupakan penyakit yang paling banyak dijumpai diseluruh dunia dengan prevalensi $4 \%$. 
Ricky Kristhanser Ndruru, Syahrial Sitorus, Nerseri Barus. Gambaran Diagnostik dan Penatalaksanaan Gastritis Rawat Inap BPJS di RSU Royal Prima Medan Tahun 2017 DOI:

Kadar glukosa dalam darah dipengaruhi oleh faktor eksogen dan faktor endogen. Faktor eksogen antara lain adalah jenis makanan yang dikonsumsi dan aktivitas yang dilakukan. Faktor endogen adalah humoral factor seperti hormon insulin, glukagon, dan kortisol ${ }^{9}$.

Berdasarkan hasil pemeriksaan endoskopi, didapati adanya mukosa lambung yang hiperemis (100\%). Pada kasus yang dicurigai gastritis dengan dilakukannya pemeriksaan endoskopi dan didapatkan adanya lesi pada gaster maka menguatkan diagnosa dari gastritis itu sendiri ${ }^{10}$.

\section{Kesimpulan}

Umur termuda adalah adalah 16 tahun dan umur tertua adalah 72 tahun. Sex ratio $=16 / 72 \times$ $100 \%=22,2 \%$. Berdasarkan kelompok umur terbanyak adalah umur $41-48$ tahun (26\%) dengan proporsi laki - laki $10 \%$ dan perempuan $16 \%$ dan paling sedikit pada umur $16-24$ tahun $8 \%$ dengan proporsi laki - laki $2 \%$ dan perempuan 6\%. Keluhan utama adalah yang terbanyak nyeri ulu hati (96\%) dan yang paling sedikit adalah muntah (4\%). Keluhan tambahan terbanyak adalah mual (98\%), diikuti muntah (85\%), perut kembung (68\%), dan yang paling sedikit adalah melena (26\%). Pada inspeksi, didapati pada pasien adanya konjungtiva anemis (29\%), pada auskultas didapati adanya peningkatan bising usus (97\%), pada palpasi didapati adanya nyeri tekan epigastrium (100\%). Pemeriksaan penunjang pada hasil pemeriksaan darah lengkap yang terbanyak yaitu di dapati adanya penurunan kadar eritrosit dalam darah (87\%) dan yang paling sedikit adalah hasil normal (13\%). Berdasarkan hasil pemeriksaan elektrolit yang terbanyak didapati adalah elektrolit dalam batas normal (85\%) dan yang paling sedikit adalah adanya ketidakseimbangan elektrolit dalam tubuh (15\%). Berdasarkan hasil pemeriksaan GDS didapati GDS normal (100\%). Dan berdasarkan hasil pemeriksaan endoskopi, didapati adanya mukosa lambung yang hiperemis (100\%). Penatalaksanaan farmakologis dengan menggunakan antasida (100\%), Domperidone (92\%), Omeprazole (89\%), Lansoprazole (11\%), Ranitidine (66\%), dan Simetidine (23\%). Serta pemasangan Intra Venous Fluid Drip (IVFD) RL (100\%).

\section{Daftar Pustaka}

1. Hadi, S. Gastroenterologi. Bandung: P.T. Alumni, 2013.

2. Gustin, R. K. Faktor-Faktor Yang Berhubungan Dengan Kejadian Gastritis Pada Pasien Yang Berobat Jalan Di Puskesmas Gulai Bancah Kota Bukittinggi Tahun 2011. Artikel Penelitian, 2012.

3. Alianto, R. Diagnosis Histopatologik Gastritis. Tinjauan Pustaka. 2015; (42):8.

4. Bpjs Kesehatan. Seputar Bpjs Kesehatan. Www.Bpjs-Kesehatan.Go.Id, 2015.

5. Tandi, J. Tinjauan Pola Pengobatan Gastritis Pada Pasien Rawat Inap Rsud Luwuk. Pharmacon Jurnal Ilmiah FarmasiUnsrat, 2017; (6): 3.

6. Sudoyo, A. W. Setiyohadi, B. Alqi, I. Simadibrata, M. Setiati, S. Buku Ajar Ilmu Penyakit Dalam Jilid 1 Edisi V. Jakarta: Internal Publishing, 2009.

7. Price, S. A. Wilson, L. M. Patofisiologi Konsep Klinis Proses - Proses Penyakit Volume 1 Edisi 6. Jakarta: ECG, 2012

8. Kementerian Kesehatan Republik Indonesia. Pedoman Interpretasi Data Klinik, 2011.

Diunduh Pada Tanggal 29 Januari 2019 Pukul 19.30]. Diunduh Dari Https://Www.Researchgate.Net/Publicatio 


\section{n/303523819_Pedoman_Interpretasi_Data}

Klinik,

9. Dewi, D. A. P. R. Pemeriksaan Kadar Gula Darah Sewaktu Pada Masyarakat Dusun Samu Mambal Kabupaten Badung, 2017. [Diunduh Pada Tanggal 29 Januari 2019 Pukul 19.30]. Diunduh Dari :

Https://Www.Researchgate.Net/Publication/26 4884054 Pemeriksaan Kadar_Gula Dara
h_Sewaktu_Pada_Masyarakat_Dusun_Sa mu Mambal Kabupaten Badung.

10. Putri, C. Y. Gambaran Klinis Dan Endoskopi Saluran Cerna Bagian Atas Pasien Dispepsia Di Bagian Rsup Dr. M. Djamil Padang. Jurnal Kesehatan Andalas, 2016. 